\title{
Challenges and opportunities in the risk assessment of existing substances in Canada: lessons learned from the international community
}

\author{
Tara S. Barton-Maclaren* \\ Existing Substances Risk Assessment Bureau, \\ Healthy Environments and Consumer Safety Branch, \\ Health Canada, 269 Laurier Avenue West, \\ Ottawa, Ontario, K1A 0K9, Canada \\ Email: tara.bartonmaclaren@hc-sc.gc.ca \\ *Corresponding author

\section{Margit Westphal}

McLaughlin Centre for Population Health Risk Assessment, University of Ottawa,

Suite 123, 850 Peter Morand Crescent,

Ottawa, ON, K1G 3Z7, Canada

Email: Margit.Geisterfer@uottawa.ca

\section{Elaha Sarwar}

Health Canada,

Ottawa, Ontario, Canada

Email: sarwar.elaha@gmail.com

\section{Donald Mattison}

McLaughlin Centre for Population Health Risk Assessment,

University of Ottawa,

Ottawa, Ontario, Canada

and

Risk Sciences International,

Ottawa, Ontario, Canada

Email: dmattison@risksciences.ca

\section{Weihsueh A. Chiu}

Department of Veterinary Integrative Biosciences,

College of Veterinary Medicine and Biomedical Sciences,

Texas A\&M University, USA

Email: weihsueh.chiu@gmail.com 


\title{
David Dix
}

Office of Science Coordination and Policy,

Office of Chemical Safety and Pollution Prevention,

US Environmental Protection Agency,

Washington DC 20460, USA

Email: Dix.David@epa.gov

\section{Robert Kavlock}

US EPAs Office of Research Development (ORD),

US Environmental Protection Agency,

Washington DC, USA

Email: Kavlock.Robert@epa.gov

\section{Daniel Krewski}

McLaughlin Centre for Population Health Risk Assessment, University of Ottawa, Ottawa, Ontario, Canada

and

Risk Sciences International,

Ottawa, Ontario, Canada

Email: dkrewski@uottawa.ca

\begin{abstract}
The evaluation and regulation of chemical substances have undergone a major overhaul in Canada, the USA and the European Union (EU) over the last decade. To facilitate increasing concerns over chemical safety, changes in regulations and strategic plans were introduced. Specifically, the Canadian parliament adopted a new amendment to the Canadian Environmental Protection Act (CEPA) in 1999, the US National Academy of Sciences published the 2007 NRC report TT21C, the US EPA developed the Strategic Plan in 2009, and the EU introduced new legislation in 2007 called Registration, Evaluation, Authorisation and Restriction of Chemicals (REACH substances). A 2013 workshop held in Ottawa (Risk Sciences International) focused on regulatory issues and challenges faced by these nations. This review summarises many of the discussions held during the workshop and specifically, five challenges that Canada has encountered when assessing chemicals with limited data on Canada's Domestic Substances List (DSL).
\end{abstract}

Keywords: Canada's Domestic Substances List; DSL; risk sciences international workshop; Chemicals Management Plan; CMP.

Reference to this paper should be made as follows: Barton-Maclaren, T.S., Westphal, M., Sarwar, E., Mattison, D., Chiu, W.A., Dix, D., Kavlock, R. and Krewski, D. (2017) 'Challenges and opportunities in the risk assessment of existing substances in Canada: lessons learned from the international community', Int. J. Risk Assessment and Management, Vol. 20, Nos. 1/2/3, pp.261-283. 
Biographical notes: Tara S. Barton-Maclaren manages a risk assessment division in the Existing Substances Risk Assessment Bureau at Health Canada. Her academic background includes a $\mathrm{PhD}$ in Pharmacology and Therapeutics with a specialisation in reproductive toxicology. As a regulatory scientist, her interests include the development of strategies for the integration of emerging data and novel methodologies for the assessment of chemicals existing in the Canadian marketplace. She participates in international initiatives under the Organization for Economic Cooperation and Development and focuses on the areas of quantitative structure-activity relationship modelling, adverse outcome pathways, integrated approaches to testing and assessment and evolving approaches to human health risk assessment in support of regulatory decision-making.

Margit Westphal is a Risk Analyst of the McLaughlin Centre for Population Health Risk Assessment at the University of Ottawa. Her academic background includes a PhD in Medical Sciences from the McMaster University, a Master's degree in Clinical Biochemistry from the University of Toronto, and a Master's certificate in Population Health Risk Assessment and Management from the University of Ottawa. Her current focus is on health risk issues related to chemical toxicity testing and prion diseases.

Elaha Sarwar is an Epidemiologist at Health Canada and a freelance health research consultant with interdisciplinary academic and professional training. Her academic background includes a BSc in Biochemistry, Graduate Diploma in Population Health Risk Assessment and Management, and expected Masters of Public Health with specialisation in Epidemiology. Her professional background includes epidemiological and public health research experience such as health outcome research, systematic literature reviews, health risk assessment, and health risk management in various disease areas.

Donald Mattison is Chief Medical Officer of Risk Sciences International and Associate Director of the McLaughlin Centre for Population Health Risk Assessment, University of Ottawa. He also serves as the Medical Advisor to QuarterWatch, Institute for Safe Medication Practices and is a Senior Research Fellow of the International Prevention Research Institute. His research interests include reproductive and developmental toxicology, pharmacovigilance and pharmacology, observational research in pharmacoepidemiology, drug safety and efficacy research.

David Dix is the Director of the Office of Science Coordination and Policy (OSCP), in the Office of Chemical Safety and Pollution Prevention of the US Environmental Protection Agency (EPA). Prior to joining OSCP, he was the Deputy and then acting Director of EPAs National Center for Computational Toxicology in Research Triangle Park, NC, where he led development of high throughput decision support tools for chemical exposure, hazard and risk. He is also an Adjunct Professor in the Department of Environmental Sciences and Engineering at the University of North Carolina, Chapel Hill. He has published over 120 scientific articles, reviews, reports and book chapters. He also serves on several journal editorial boards and has represented EPA at a wide range of national and international meetings.

Weihsueh A. Chiu is a Professor in the Department of Veterinary Integrative Biosciences in the College of Veterinary Medicine and Biomedical Sciences at Texas A\&M University. His academic background includes a PhD in Physics and a Certificate in Science, Technology, and Environmental Policy, both from Princeton University. Prior to joining Texas A\&M University, he worked at the US Environmental Protection Agency for over 14 years. His research has 
focused on human health risk assessment, particularly with respect to toxicokinetics, mechanisms of toxicity, physiologically-based pharmacokinetic modelling, dose-response assessment, and characterising uncertainty and variability. He has also served on multiple committees and workgroups for the World Health Organization's International Agency for Research on Cancer and International Program on Chemical Safety, and for the US National Academy of Sciences.

Robert Kavlock is the Deputy Assistant Administrator for Science in the US EPAs Office of Research Development (ORD), Washington DC. ORD is the scientific research arm of EPA, whose leading-edge research helps provide the underpinning of science and technology for the Agency. He is responsible for overseeing the national research programs for the Office, which has 1,700 staff located in 13 facilities across the USA and an annual budget in excess of $\$ 500 \mathrm{M}$. His previous position was that of founding Director of the National Center for Computational Toxicology (NCCT) within EPA. The NCCT has pioneered the application of modern molecular biology and computational sciences through its ToxCast program to bring high throughput methodologies to the study of chemical effects on biological systems. Prior to that, he spent 15 years as the Director of the Reproductive Toxicology Division in ORD where he focused on improving approaches to risk methods for non-cancer health outcomes.

Daniel Krewski is a Professor in the School of Epidemiology, Public Health and Preventive Medicine at the University of Ottawa, where he also serves as the Scientific Director of the McLaughlin Centre for Population Health Risk Assessment. His research interests include epidemiology, biostatistics, risk assessment, and risk management. He is a Fellow of the Society for Risk Analysis, the American Statistical Association, and a National Affiliate of the US National Academy of Sciences. He holds the Natural Sciences and Engineering Research Council of Canada Chair in Risk Science at the University of Ottawa.

This paper is a revised and expanded version of a paper entitled 'Application of IATA to existing substances in Canada' presented at Health Canada Training Seminar on Risk Science in the 21st Century, University of Ottawa, Ottawa, Ontario, Canada, 4-6 March 2013.

\section{Introduction}

Risk Science International (RSI) (http://www.risksciences.com/) held a workshop on Risk Science in the 21st Century in Ottawa, Ontario, in March 2013, to facilitate an interactive multi-sector dialogue on the state-of-the-science in risk assessment, to outline the current progress in chemical risk assessment strategies amongst different agencies internationally, to identify areas of common interest, and to explore the advanced risk science technologies. Workshop speakers and participants included stakeholders from the European Union (EU), the USA and Canadian governmental and regulatory agencies, research institutes, and academia. This paper outlines the challenges, as well as possible opportunities regarding tools and methodologies, in an effort to offer ways of approaching the risk assessment of a large number of chemicals, many of which have limited or no empirical toxicological data. Discussion groups focused on the Canadian 
regulatory challenges and offered possible solutions regarding risk assessment of datapoor chemicals based on global experience.

In Canada, the Canadian Environmental Protection Act (CEPA), 1999 is the legislative framework for the management of chemicals and is an extension of the previously implemented environmental law created in the late 1980s (Government of Canada, 2007). CEPA 1999 covers a range of activities to protect human health and the environment; the main component of this act is the management of chemical substances (Environment Canada, 2007). Canadian Environmental Protection Act (1999) mandated an evidence-based approach to identifying and implementing government action on chemicals. In part 5 of the act, Environment Canada and Health Canada share the task of conducting risk assessment and management measures associated with those substances concluded to pose a risk to the environment or to human health as set out under CEPA 1999 (Government of Canada, 1999; Environment Canada, 2015). CEPA reform requires that all newly manufactured and imported chemicals entering the Canadian market are to be screened and assessed under specific criteria before allowing their use (Government of Canada, 2007).

The Chemicals Management Plan (CMP) is a Government of Canada initiative established in 2006 aimed at reducing the risks posed by chemicals to Canadians and their environment by managing the assessment of 23,000 existing chemicals registered on the Domestic Substances List (DSL) and which may be present in the Canadian market (Environment Canada, 2007). The CMP, delivered collaboratively by Environment Canada and Health Canada, builds on previous initiatives to provide an integrated, government-wide approach to chemicals management, and set clear priorities and timelines for assessing and managing chemical substances used in Canada (Health Canada, 2009). Under the provision of the CMP, Canada completed a systematic categorisation the DSL to identify those that were priorities for assessment or further research, and those in need of action to protect human health and the environment (Environment Canada, 2015; Government of Canada, 2007).

The Ministers of Health and of the Environment undertook Categorization of the approximately 23,000 existing chemicals on the DSL by applying specific criteria including the greatest potential for exposure (GPE) of the general population, persistence or ability to bio-accumulate and those considered to be inherently toxic to humans (Environment Canada, 2013; Health Canada, 2009). Categorisation of the DSL resulted in the identification of substances that represented the highest priorities for action based on potential for exposure, hazard and/or risk to human health and was essential for prescribing reporting requirements for existing substances, for the generation of screening risk assessments for much larger numbers of substances, and for the development of appropriate risk management tools and approaches. Pursuant to the commitment of targeted action on chemicals of higher concern in support of an international framework, the Strategic Approach to International Chemicals Management (SAICM), the CMP intends to address all 4,300 existing substances identified as priorities by 2020 . Approximately 1,100 existing substances have been addressed under the first phase of the CMP (2006-2011), and about 1,700 additional substances are currently being assessed as part of the second phase of the CMP (2011-2016) through various initiatives. The remaining approximate 1,500 priority substances will be addressed under the third phase of the CMP by 2020 (Environment Canada, 2013). 
The USA and EU have approached the regulatory challenge of chemical risk assessment very differently. This discussion paper based on the workshop presentations and discussions from the Risk Sciences International workshop held in Ottawa, March 2013, lists a series of challenges and opportunities faced by the Canadian Government and how the approaches used by other governments could support Canada in its decision-making process under the CMP moving forward.

\section{Regulatory challenges and opportunities in 21 st century risk assessment}

Since 2007, when the NRC report, 'Toxicity Testing in the 21st Century: A Vision and A Strategy' (TT21C) was published (National Research Council, 2007), toxicity testing has focused on the feasibility of using in vitro methods for risk assessment. This report proposed a shift away from in vivo models towards a model centred on in vitro and in silico methodologies. A second NRC report, published in 2009, proposed a parallel modernisation of risk assessment methodologies to better inform risk management decisions and to better characterise population health risks (National Research Council, 2009).

The need for change and the evolution of toxicology was a major theme conveyed by many of the speakers present at the workshop. Hartung [Professor and Chair for Evidence-based Toxicology, Director at the Center for Alternatives to Animal Testing (CAAT)] noted that many toxicological methodologies depend on lengthy and laborious animal model experiments, are conducted at high substances concentrations and require uncertainty factor modifications to extrapolate to expected human responses at lower doses. With advances in toxicology and molecular biology, major improvements are envisaged in the state of the science for hazard identification, dose response and exposure assessment. The Human Toxome Project headed by Hartung aims to comprehensively map molecular pathways of toxicity (PoT), defined by cellular processes shown to mediate adverse outcomes, for endocrine disruption using complementary omics approaches such as metabolomics, transcriptomics, and proteomics (Hartung and McBride, 2011). Bouhifd et al. (2015) outline a series of eight challenges that have to be met in order to complete this project.

Kavlock described the US EPAs Computational Toxicology Research Program (CompTox), which employs HTS and other new in vitro and in silico methodologies for better understanding and predicting risks associated with environmental chemicals. Defined as a technology-based, hypothesis-driven effort to increase the soundness of regulatory and risk assessment decisions within the US EPA, the CompTox research program builds the capacity to prioritise, screen, and evaluate chemicals by enhancing the predictive understanding of toxicity pathways. Approaches undertaken in the CompTox program involve identifying targets or pathways linked to toxicity, identifying the nature and dose of the chemicals that perturb these targeted pathways which lead to adverse events, and probing assays for targeted assessment to prove key events in the pathway perturbation (Kavlock et al., 2012; US EPA, 2016a).

Tomasz Sobranski [Computational Assessment Unit, European Chemicals Agency (ECHA), Helsinki, Finland] presented changes in chemical management in the EU. ECHA established in June 2007, manages Registration, Evaluation, Authorisation and Restriction of Chemicals (REACH substances) an act that regulates chemical substances in commerce in the EU. REACH is a consolidation of more than 40 chemical regulations 
with the overall mandate to "improve the protection of human health and the environment from the risks that can be posed by chemicals, while enhancing the competitiveness of the EU chemicals industry". The regulation also aims to promote alternative and new in vitro methodologies for the assessment of the hazards of substances in order to reduce the number of tests on animal models (ECHA, 2016).

Introducing principles that respond to the challenges and opportunities currently facing risk assessment and chemicals management, Krewski presented the recently published framework for the next generation of risk science. It was hypothesised that the evolution in toxicity testing would provide new methodologies to support broad characterisation of chemicals, including toxicity end points or outcomes, life stage analysis, and analysis of chemical mixtures. A robust scientific basis for environmental health risk assessments would be developed by amalgamating data on mode of action, dose-response, and human exposure-based primarily on in vitro testing, computational systems biology pathway models and expanded use of high-throughput (HT) biomonitoring data, respectively (Krewski et al., 2014). New scientific approaches were also acknowledged in the lectures by Hartung and Meunier, including the added benefit of reducing the use of animal models for testing (Schoeters, 2010; Hartung and McBride, 2011; Bouhifd et al., 2015). Challenges of researching, validating, accepting and implementing these new approaches in the context of human health risk assessment and regulatory decision-making were discussed throughout the workshop; five key challenges will be highlighted in this paper.

\subsection{Challenge 1: how to address data-poor chemicals}

One of the main and continuing challenges for chemical risk assessment internationally mentioned during the RSI workshop is the high number of chemicals with limited toxicological information currently in commerce. Barton-Maclaren highlighted that this paucity of data poses some challenges and introduces opportunities for the application of new approaches for moving forward under the next phase of the CMP (CMP3). Early analyses of data availability revealed that a large number of the substances appeared to have limited information with a major portion of these having no conventional toxicological data. The remaining substances have some evidence-based data but only a small percentage of CMP3 substances are considered to be 'data rich' (i.e., > 1,000 records or references based on a preliminary screening across selected databases; the data quality of these records remains to be evaluated). The data needs as determined by this preliminary data search for purposes of problem formulation were expected to constitute challenges and opportunities in the risk assessment process for the third phase of the CMP.

The requirement to assess chemicals with data gaps is a challenge that is not unique to Canada; both the USA and the EU have faced similar dilemmas. Several workshop presenters emphasised that the use of HTS assays could rapidly screen thousands of chemicals, giving some priority to the enormous number of potential chemical assessments. Kavlock and Dix from the US EPA spoke about the primary mandate of US EPAs CompTox ToxCast program, which was to address the massive data gaps and decrease time and costs related to producing data on bioactivity and adverse effects of chemicals through the development of in vitro assays (US EPA, 2016a). Figure 1(a) provides a summary of the selection process of the current set of ToxCast assays. 
Figure 1(b) depicts the overlap between the ToxCast HTS assays, and the ultraHTS assays run as part of the US Government-wide Tox21 partnership between EPA, NIH and FDA. The process began with ToxCast Phase I, wherein almost 300 data-rich chemicals (mainly pesticides) were tested in more than 600 HTS assays, and then Phase II in which 767 chemicals were tested in almost the same set of assays as Phase I. ToxCast Phase I and II HTS assay results link over 1,000 chemicals with interactions involving biological pathways associated with poor health outcomes (Judson et al., 2010), and predictive models from ToxCast HTS assay data were developed for reproductive toxicity (Martin et al., 2011), vascular development (Kleinstreuer et al., 2011), and development toxicity (Sipes et al., 2011). Both speakers emphasised the valuable application of HTS assays, and though HTS assays at this point in time may not be sufficient for quantitative risk assessments, HTS could provide enough information on untested and/or data-poor chemicals to support prioritisation and screening of chemicals for further testing and evaluation (Judson et al., 2013, 2014). The Margin-of-Exposure framework introduced by Thomas et al. (2013) and the Toxicological Prioritisation Index (ToxPi) presented by Dix (Reif et al., 2010, 2013) (both discussed later in this paper) are examples of tools that use HTS assay data for the prioritisation of chemicals.

Figure 1 National Chemical Genomics Center (NCGC) high throughput screening assays, (a) overview of NCGC HTS assays (b) overlap among HTS programs

\begin{tabular}{l|c|ccccc}
\hline \multicolumn{2}{l}{$\begin{array}{l}\text { Screening } \\
\text { program }\end{array}$} & \multicolumn{1}{c}{ Chemicals } & Assays & Endpoints & Completion & Available \\
\hline $\begin{array}{l}\text { ToxCast } \\
\text { Phase I }\end{array}$ & 293 & $\sim 1,100$ & 2011 & Now & Now \\
\cline { 2 - 5 } $\begin{array}{l}\text { ToxCast } \\
\text { Phase II }\end{array}$ & 767 & $\sim 1,100$ & Fall 2012 & 2nd Q 2013 & 2nd Q 2013 \\
\cline { 2 - 5 } $\begin{array}{l}\text { E1K } \\
\text { (endocrine) }\end{array}$ & 880 & $\sim 120$ & Fall 2012 & 2nd Q 2013 & 2nd Q 2013 \\
\cline { 2 - 5 } Tox21 & 8,193 & $\sim 50$ & Ongoing & $\begin{array}{c}\text { Beginning } \\
\text { 2013 }\end{array}$ & $\begin{array}{c}\text { Beginning } \\
\text { 2013 }\end{array}$ \\
\hline
\end{tabular}

(a)

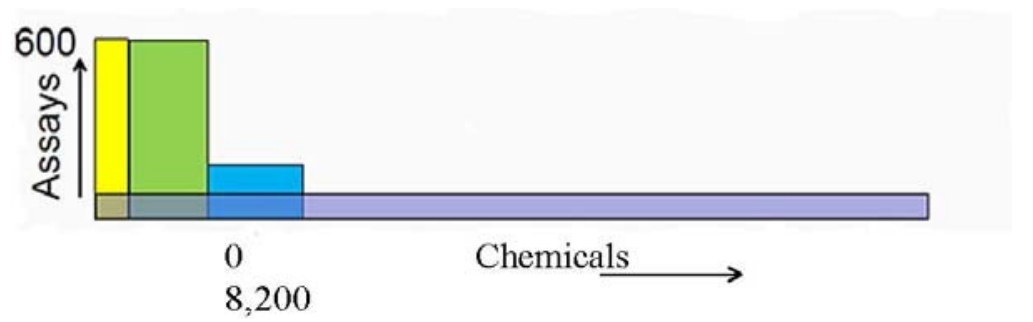

(b)

Source: Dix (2013)

Menghang Xia [Division of Pre-Clinical Innovation, National Center for Advancing Translational Sciences (NCATS), National Institutes of Health] presented work done by the NIH Chemical Genomics Center (NCGC) as part of the Tox21 US Government collaboration. This facility runs ultra HTS assays [Figure 1(a) and Figure 1(b)] with a 
robotics system capable of running one hundred 1,536 well microtiter plates per day. Each plate can test 1,408 samples, therefore close to one million data points can be processed in one week. NCGC is currently testing over 8,000 chemicals for Tox 21 over a wide dose range in these ultra HTS assays (Shukla et al., 2010; Hsu et al., 2016).

In contrast to Canada and the USA, the EU's REACH legislation places the burden of testing for chemical safety on industry, importers, and downstream users (ECHA, 2016). At the same time, the EU Cosmetics Directive promotes the 3Rs to replace, reduce, or refine the use of testing methods on animals (Schoeters, 2010). Jean-Roch Meunier (CEO at Medicen Paris Region) discussed the EU Cosmetics Regulation and the ban on animal testing that occurred in 2013 (European Commission, 2013). Many in vitro methods were not validated testing methods and at this point in time the methods were considered to be 'innovation-accelerating and prioritisation tools (structure activity, molecular design, and prioritisation purpose)', and are not yet ready as stand-alone risk assessment tools (Adler et al., 2011). The EU Commission has partnered with Cosmetics Europe, an association representing member companies and associations in the cosmetics and personal care industry, and collaboratively they have invested in a project called SEURAT-1 (http://www.seurat-1.eu/). The SEURAT project investigates several different branches of research for alternative methods that can be used in risk assessment (Rovida et al., 2015).

Consistent with the views of numerous other panellists and speakers, Barton-Maclaren acknowledged that the robotic-automated system of HTS assays have the potential to efficiently and quickly screen thousands of chemicals simultaneously, at multiple doses, for bioactivity related to a wide range of biological pathways. HTS offers reduced cost of testing, has the ability to profile a large number of chemicals, and allows human molecular targets and cell systems to be directly interrogated. However, it is acknowledged that HTS is not capable of testing the level of complexity found in the whole organism, and only short-term cell-based effects can be studied using HTS assays. Also, it is important to note that not all chemicals can be tested in HTS due to the need to meet certain criteria as outlined in the next section, underscoring the need for alternate and complementary methods and approaches for both prioritising and assessing of data-poor chemicals.

\subsection{Challenge 2: can toxicity pathways predict adverse outcomes}

With regards to using HTS for assessing the potential risk associated with chemicals, workshop attendees heard from Hartung, that there are a number of different challenges and limitations associated with this approach. He outlined that cell-based assays may not always exactly predict biological effects since cells do not get diseased (Hartung et al., 2013). As previously mentioned, both Hartung and Kavlock have also pointed out that not all chemical compounds can be screened in HTS. Certain chemical characteristics must be met for suitability in HTS screening such as a chemical's availability, purity, solubility, stability, and minimal volatility. Also, the metabolic properties of chemicals are difficult to establish in a single cell format, and it is not possible to integrate effects of parent and metabolites, or to establish interactions among different cell types (Hartung et al., 2013). Mechanistically, similar assays are expected to yield some degree of discordance due to the biological complexities and chemical-assay specific interference (Judson et al., 2013). Therefore, it is unlikely that a single in vitro assay will yield a 
perfect result and integrated testing strategies (ITS) that measure a wide range of data, chemical characteristics, and diverse pathways are needed. For example, a mode of action for skin sensitisation is being broken down into its basic components, and all the responses possible are represented in a series of in vitro assays, that was originally one test, the local lymph node assay (LLNA) (MacKay et al., 2013). Kleinstreuer et al. (2014) recently screened a set of 60 training chemicals in a HTS assay set based on key events in the adverse outcome pathways (AOP) of skin sensitisation. This assay set had $80 \%$ concordance with the murine LLNA indicating that efficient assay strategies in the future could replace animal testing.

Rovida et al. (2015) summarised discussions, developments and challenges of a recent ITS workshop where testing for skin sensitisation was used as a case study example in the report. The biological mechanism, along with key events, has been well characterised for skin sensitisation. However, there are several factors that impede ITS from moving forward quickly including a lack of agreement within the scientific and regulatory communities at present on the ITS approach itself, and currently, there is no validation procedure for ITS regulatory acceptance. The Organization for Economic Co-operation and Development (OECD) has published several reports on ITS (or) Integrated Approach on Testing and Assessment (IATA), advocating that when the AOP is known, a series of tests based on key molecular events along the pathway could replace current animal tests (OECD, 2012a, 2012b). A recently published guidance document (OECD, 2014a) describes a well-defined ITS for both skin corrosion and irritation.

David Dix presented the ToxPi as a tool that integrates all types of data including series of in vitro pathways for chemical prioritisation. ToxPi is a flexible tool for ranking chemicals based on weight-of-evidence for different prioritisation tasks. It combines what is known about a chemical (in vitro, in vivo, pathways and exposure), numerically integrates critical information from the disparate data sources and organises them visually into a circle with components represented as colour coded slices to distinguish the types of in vitro assays, chemical properties and pathways associated with the chemical of interest. The size of slices varies depending on the scale of influence a particular piece of data may have. Slices can be continually added to the pie thereby changing the ranking of toxicity of a chemical (Reif et al., 2010). ToxPi profile ranking has been used to rank chemicals based on embryonic development. HTS assays based on inflammatory chemokine signalling, plasminogen-activating systems, and vEGF pathway changes were ranked and compared with chemical ranking based on in vivo toxicity data (Kleinstreuer et al., 2011). Further, exposure data and measurements can be incorporated and change the ToxPi ranking of a chemical based on bioaccumulation, bioconcentration and persistence in the environment (Gangwal et al., 2012). The implementation of an interactive ToxPi graphical user interface (GUI) application facilitates the analysis and communication of the ToxPi results and relative prioritised ranks to support various decision-making contexts in environmental health (Reif et al., 2013).

Exposure data is an important counterpart to in vitro HTS data. Elaine Cohen Hubal [Senior scientist, US EPAs National Center for Computational Toxicology (NCCT)] described US EPAs ExpoCastTM project, which employs models (far-field and near-field) capable of quantitatively predicting exposure determinants in a high throughput manner. Model predictions are compared with biomonitoring data from the CDC NHANES study and calibrations adjusted with levels of uncertainty for near-field exposures. A new mechanistic model, The Stochastic Human Exposure and Dose Simulation Model for Multimedia, Multipathway Chemicals (SHEDS-MM), has been 
developed to assist in HT exposure assessment for residential and dietary intakes (Isaacs et al., 2014; Wambaugh et al., 2013). Dix discussed that comparison of estimated steady state exposure levels determined from ToxCast ${ }^{\mathrm{TM}}$ data and ExpoCast ${ }^{\mathrm{TM}}$ approaches can be used as an initial, risk-based approach for screening and assessment of data poor chemicals (Judson et al., 2014).

These approaches are complimentary to the margin of exposure (MOE) framework presented by Thomas et al. (2013). HTS in vitro assays can be used to estimate chemical-specific biological pathway altering doses or BPADs using reverse toxicokinetics (RTK) where the BPAD combines does-response data consistent with current risk assessment metrics coupled with estimates of uncertainty and population variability. Estimated population exposure levels of the chemical are compared to BPAD values. The MOE is the comparison between these two values (BPAD and estimated population exposure levels) and is the level that risk assessors determine is the safest level of difference between the two before a chemical is tagged for further assessment. This MOE could be a 10-fold to 1,000-fold difference or more between what dose has been determined to cause a response in the in vitro assays (BPAD) and what is estimated to be in the environment (Judson et al., 2011; Wetmore et al., 2012). As shown in Wetmore et al. (2012) for the majority of the Phase I ToxCast chemicals evaluated, the activity to exposure ratio range (a metric comparable to the MOE) which compares the human oral equivalent doses derived from the HTS data with human exposure estimates are separated by several orders of magnitude. Thomas et al. (2013) presented a tiered framework with the first tier point of departure (POD) evaluation of chemicals with 'potential biological perturbation' tagged for second tier analysis. Second tier analysis involves chemical exposure to primitive in vivo systems. Only chemicals tagged for third tier analysis are involved in traditional animal studies. Recent works by Wetmore et al. (2015) have filled in data gaps for exposure estimates of many of the ToxCast chemicals.

Krewski presented the NexGen tiered approach to human health risk assessment originally published by Cote et al. (2012). The first of the three tiers in the proposed assessment paradigm uses high throughput in vitro assay data coupled with in silico [quantitative structure-activity relationship (QSAR)] analyses for screening and prioritisation of chemicals. The second tier, limited scope assessments, incorporate more complex in vitro systems (including medium throughput and high content data) along with select conventional animal data. Finally, tier 3, in-depth assessments, target chemicals that are of major regulatory importance; consequently all complex mammalian systems and policy-relevant data is included to increase the robustness of the analysis for decision-making. During his presentation, Krewski introduced new methodological issues that are key for the extrapolation of in vitro testing for the characterisation of population health risks and for the application of the NexGen approach to risk assessment. These issues were contrasted with the current approach and include considerations for:

1 adverse outcomes

2 dose-response assessment

3 variability

4 susceptible populations

5 dose and species extrapolation 
6 mixtures

7 uncertainty analysis.

The NexGen project included a series of case study prototypes to investigate the practical application of the tiered framework and the available scientific tools and techniques in risk science. The NexGen framework for risk-based decision-making aims to transform the human health risk assessment process to one that focuses on characterising risk of critical toxicity pathway perturbations. Based on the illustrative examples, there is already a transition in the technologies that are being incorporated into toxicity testing and risk assessment paradigms (Krewski et al., 2014).

Tara Barton-Maclaren shared the opinion of several other workshop speakers that integrated testing approaches with in vitro metrics to determine POD values would be useful approaches to explore in support of screening and risk assessment activities for the current and future phases of the CMP. Although current in vitro assays cannot directly predict adverse apical endpoints for comprehensive hazard characterisation per se, the analysis of dose-response curves generated from HTS assays, used in combination with other methods such as QSAR and read-across [including in vivo data from similar substances], and when compared with exposure data to determine a MOE is considered a cost-effective and efficient approach to support risk assessment activities and regulatory decision-making.

\subsection{Challenge 3: data availability on an international level for subsets of chemicals}

Data sharing among international governments is already underway. When international governmental agencies share their data results for toxicity assessment, other countries that do not have in-house systems (such as the NCATS laboratories in the USA) can benefit from subsets of chemicals that have online information freely available. For example, many of the chemicals listed for assessment under the three phases of the CMP overlap with chemicals in the USA, EU, as well as other jurisdictions.

In the USA, the collection, standardisation, storage, and integration of all applicable data on chemicals was a primary goal of the US EPA (2009) Strategic Plan and both Dix and Kavlock discussed some of the uses for the searchable online bioinformatics databases (developed by US EPAs CompTox program). For example, Aggregated Computational Toxicology Resource (ACToR) is an online database that aggregates all publicly available chemical toxicity data from over 1,000 public sources on over 500,000 environmental chemicals and is searchable by chemical name, other identifiers and by chemical structure. This database warehouse also contains data from other US EPA chemical toxicity databases including:

1 ToxRefDB (30 years and \$2 billion worth of animal toxicity studies)

2 ToxCastDB (data from screening 1,000 chemicals in over 500 HT assays)

3 ExpoCastDB (consolidate and link human exposure and exposure factor data for chemical prioritisation)

4 DSSTox (provides high quality chemical structures and annotations). 
US EPA has launched a user-friendly software tool that will allow risk assessment to take place on the desktops of users without the need to be an IT specialist; this tool is called the Interactive Chemical Safety for Sustainability (iCSS) Dashboard (US EPA, 2014, 2016b).

Richard Becker (Toxicologist at American Chemical Council) discussed OECD, which is an international organisation established in 1961 to stimulate world trade and economic progress. Their mission is to 'promote policies that will improve the economic and social well-being of people around the world' (OECD, 2015a), and consists of 34 industrialised member countries. In 1987, a national program to cooperatively investigate existing high production volume (HPV) chemicals was established. This program allowed for all the member countries to share the burden of assessing the chemicals and share the information gained from those assessments (OECD, 2015b). In addition, the OECD has set up eChemPortal, a website based on the collaboration of many counties and organisations to make collections of information on chemicals publically available (OECD, 2016a). Participating databases include EU CHEM, which gives information based on REACH dossiers, ACToR from the US EPA and many others (OECD, 2016b).

Workshop presenter, Barton-Maclaren, outlined international programs where there are overlaps of chemicals space that might help to inform some of the challenges associated with risk assessment of the large volume of data limited substances in Canada (see Figure 2). For example, Figure 2(a) illustrates the proportion of substances on the DSL to be addressed under the CMP that overlap with other international programs. These include REACH, information collected (or being collected) through the OECD HPV program, substances identified under the Australian prioritisation framework [Inventory Multi-tiered Assessment and Prioritisation (IMAP)], and a number of substances have some health effects information generated through the US HPV chemical program.

Notably, there remain $53 \%$ of CMP chemicals that have no overlap with other international regulatory programs. In addition, there is also substances overlap with the high throughput screening (HTS) programs in the USA including ToxCast, Tox21 and the Endocrine Disruptor Screening Program (EDSP). As shown in Figure 2(b), approximately $16 \%$ of the total CMP chemical list (including all phases) has HTS data; it is anticipated that this percentage will continue to increase as data from additional phases of the US programs is released. Specific to future assessment priorities moving forward under CMP3, HTS data is currently available for approximately 270 chemicals. Although the overall chemical overlap represents a modest proportion of the total number of substances that remain to be addressed under the CMP, the toxicological data developed to support work in other jurisdictions are among the promising solutions for addressing the data availability challenge, where data generated or released to support registration in other jurisdictions, such as REACH, OECD, and other national prioritisation programs, can be accessed and used to inform risk assessments under the CMP. 
Figure 2 Chemical space overlap between substances to be addressed under Canada's CMP and other international regulatory and data generation programs, (a) regulatory programs (b) data generation programs

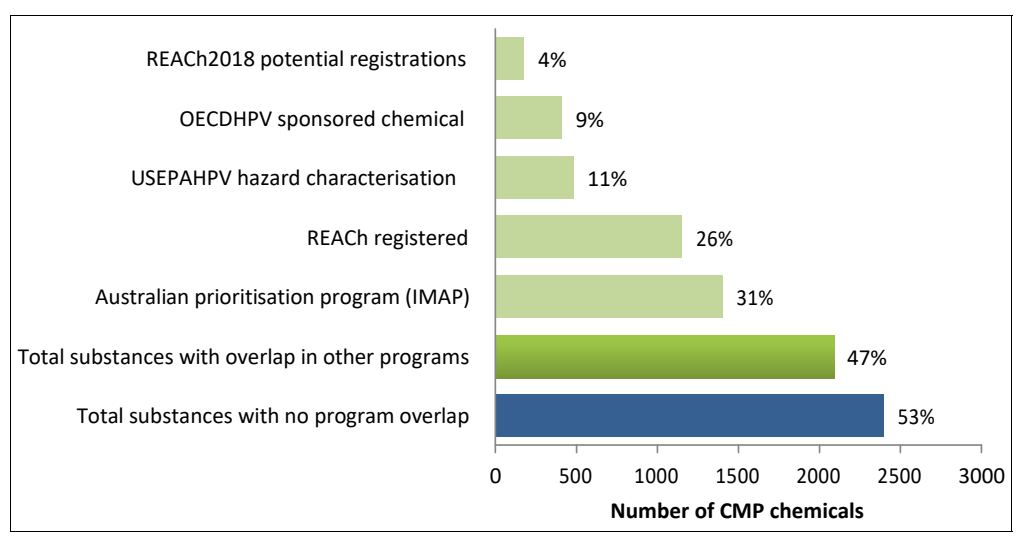

(a)

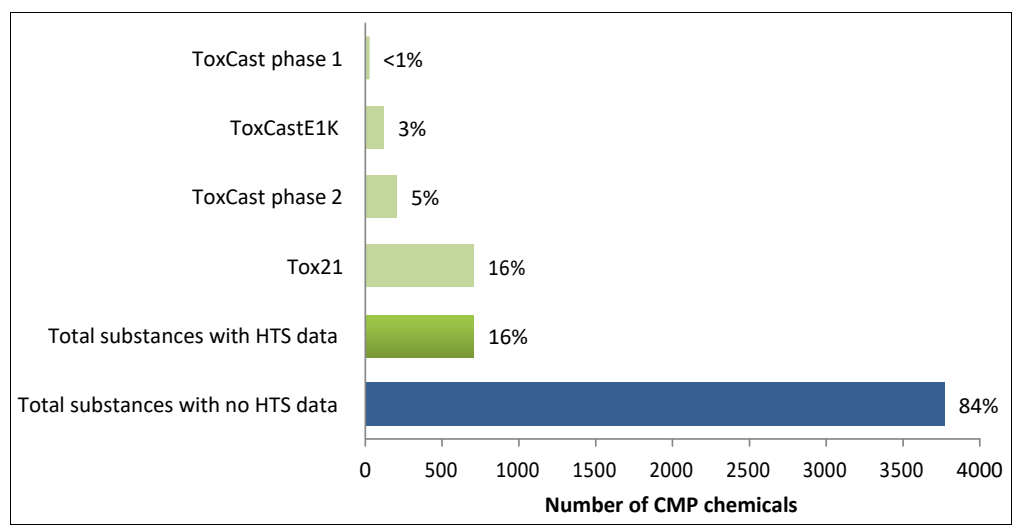

(b)

\subsection{Challenge 4: increasing awareness and acceptance of emerging technologies related to hazard identification and risk assessment}

Realisation of the TT21C vision entails acceptance and understanding from diverse stakeholders. TT21C faces many challenges and these were illustrated and discussed by the different groups at the RSI Workshop. Since the original endorsement of TT21C by the scientific community was received in 2008 (Collins et al., 2008) intense discussions among academic, industrial, pharmaceutical, and governmental agencies have allowed for enhanced understanding of the vision along with its limitations. Three sets of reviews and commentaries have been published debating the advantages and disadvantages of the new vision for the testing of chemicals and risk characterisation, including: 
1 eight commentaries in Toxicological Sciences (2009) (Andersen and Krewski, 2010)

2 six commentaries in Risk Analysis (2009) (Greenberg and Lowrie, 2009)

3 reprints of both original NRC report (National Research Council, 2007) and the US EPA strategic plan (US EPA, 2009), including 14 additional papers in a special issue of the Journal of Toxicology and Environmental Health (JTEH, 2010).

These streams of commentaries and reviews explore and discuss how the new scientific tools and techniques could be used, the challenges that these new techniques face, how quality bioinformatics databases need to be standardised, and how definitions of reference dose, mode of action, validity, and other key components of toxicity testing will evolve over the next 20 years.

Overall, the leading authorities in risk science endorse the NRC vision and agree that the new in vitro methods could be used to prioritise the enormous backlog of data-poor chemicals in a timely, cost-effective manner. Chemicals could be tested at dose response amounts equivalent to estimated current human exposure levels in human cells eliminating one level of uncertainty extrapolations (Conolly, 2009; Kavlock et al., 2009). Many authors felt that a number of challenges still needed to be overcome before TT21C would be fully functional including current knowledge gaps associated with toxicity-related pathways versus normal homeostatic responses (Hattis, 2009; Tsuji and Garry, 2009). Another recurring theme is whether in vitro methods could predict in vivo outcomes, although many scientists believe that the current method of high-dose exposures in animal models extrapolated with uncertainty factors is far from perfect (Andersen and Krewski, 2010). The standardisation and quality of bioinformatics databases is a key issue as well (Judson et al., 2010; Kavlock and Dix, 2010).

The advancement of how these new scientific methods could be incorporated into hazard identification and dose-response assessment for risk assessment continued with the launch of the US EPAs 'Advancing the Next Generation of Risk Assessment (NexGen)' program. One of the mandates for the NexGen program was to engage the public and stakeholders in the process and hold informative workshops. As previously described, the program investigated several detailed case study prototypes under three tiers of risk assessment and a final report on the results of this program is available online (US EPA, 2015a).

AXLR8 presented by Troy Seidle (HSI Director of Research \& Toxicology, AXLR8 Project Associate Coordinator) is an organisation funded by the European Commission Directorate General for Research and Innovation under the 6th and 7th European RTD Framework Programme Health Theme, and goals include assisting in the transition to a toxicity pathway risk-based evaluation process and to promote increased stakeholder and public awareness (AXLR8, 2016a). AXLR8 has published five alternative testing strategies progress reports on advancement of scientific tools and techniques (AXLR8, 2016b), and held annual workshops to promote dialogue and collaboration (AXLR8, 2016c). 


\subsection{Challenge 5: the integration of emerging technologies and in vitro data into risk assessment under various regulatory statutes.}

In Canada, CEPA 1999 covers a range of activities to protect human health and the environment against the risks from chemical substances. While the regulatory statute is not prescriptive regarding how toxicity testing should be done, it sets out processes for risk-based approaches which rely on sound science, assessment and monitoring and requires the incorporation of weight of evidence and precaution to reduce risks of toxic substances (Government of Canada, 1999). Accordingly, under the legal act, risk assessment approaches for existing substances can be flexible and adaptable to a range of substances and groups of substances with varying amounts and types of information, including emerging scientific knowledge and assessment technologies. In Canadian law, an experienced person who is qualified and familiar with the technique can assert the validity of any result obtained (Miller, 2015).

In the USA, the Toxic Substances Control Act (TSCA) that regulates the use of chemicals in commerce also appears to be compatible with integrating new technologies and advancing science under the regulatory statute. TSCA (Section 4) states that appropriate testing methodologies should be considered by the US EPA and lists in vitro tests as one of its methodologies. TT21C techniques do not require any amendment to TSCA for its implementation (Locke and Myers, 2011; Locke et al., 2016). In US federal law, normally, this is expressed roughly as

1 whether the theory or technique is falsifiable, refutable, and/or testable

2 whether it has been subjected to peer review and publication

3 the known or potential error rate

4 the existence and maintenance of standards and controls concerning its operation

5 the degree to which the theory and technique is generally accepted by a relevant scientific community (Miller, 2015).

In the EU, companies are required to register their substances with ECHA, and to identify and manage the risks associated with those substances to comply with the regulation. Companies have to demonstrate to ECHA how the substances can be used safely, and at the same time must communicate the risk management measures to the users (ECHA, 2016). Collaboration between companies registering the same substances is allowed. The first act to make the TT21C vision law was the new EU Cosmetics Regulation $1223 / 2009$, which was fully implemented in 2013, and does not allow any animal testing on cosmetic products (European Commission, 2013). The ban was implemented even though many of the alternative testing methods were not yet available or validated (Hartung et al., 2010, 2013).

OECD (presented by Richard Becker) is committed to providing a platform to compare policy experiences and coordinate domestic and international policies of its members. In the area of in vitro toxicology, OECD is leading an effort to establish universal testing guidelines applicable to all chemicals and provide guidance on regulatory acceptance of new or revised methods at an international level (OECD, 2012a, $2012 b, 2014 a)$. Once a test method has been validated, member countries meet and agree on test guidelines. OECD supports the "harmonization of international regulatory acceptance of adequately validated test methods", OECD Test Guidelines are accepted 
among member countries, and in some non-member countries (OECD, 2015c). OECD has also published a guidance document, 'Guidance Document on the Validation and International Acceptance of New or Updated Test Methods for Hazard Assessment' (GD 34 ) to standardise and achieve global consistency in the validation, evaluation, and review regarding test methods $(\mathrm{OECD}, 2005)$. GD 34 provides guidance on key factors such as:

1 approaches to validation

2 the design and conduct of validation studies

3 independent evaluation at national level

4 international level peer review of a validation study

5 international regulatory acceptance of validated tests

6 documentation required for supporting a validation study

7 criteria for successful regulatory acceptance (Schechtman, 2008).

More recently, the OECD series on testing and assessment has focused efforts on the development of test guidelines and respective guidance in emerging areas such as integrated approaches to testing and assessment (OECD, 2008, 2014a, 2015d), developing and assessing AOP (OECD, 2013), and non-guideline in vitro test methods (OECD, 2014b, 2014c). These and various other guidance documents and validation reports are available online through the OECD Series on Testing and Assessment (http:/www.oecd.org/chemicalsafety/testing/seriesontestingandassessmentpublicationsby number.htm). Canada as a member country actively contributes to the Test Guidelines Program as well as several other ongoing projects and initiatives under the OECD. The international collaborations, harmonised guidance and approaches developed through OECD task forces and working groups support further understanding and advancement of risk assessment principles and practices that integrate emerging technologies. International fora to discuss how the evolving methodologies and approaches are used by comparable regulatory authorities for chemical assessment results in a better understanding of issues of international concern, facilitates information and data exchange, and enhances the mutual acceptance of assessments from legislated regulatory counterparts.

\section{Summary and conclusions}

The innovative toxicity testing strategies presented in the $\mathrm{TT} 21 \mathrm{C}$ report promises a cost-effective, timely, and efficient approach to address the thousands of chemicals under environmentally relevant concentrations in commerce needing assessment of their potential risk to human health and the environment. For instance, the use of in vitro HT methodologies has the to potential to provide a more efficient and cost-effective means to screen and prioritise tens of thousands of chemicals for further assessment, and could be considered for many of the data-poor chemicals requiring assessment under various regulatory jurisdictions, including a subset within the CMP. With further research and understanding of toxicity pathways, the potential for hazard identification and 
characterisation using HTS data and predictive models will continue to develop beyond current applications to prioritisation and screening after this workshop (US EPA, 2015b). However, as concluded by the HESI workshop, 2011, the most suitable use for high throughput technology is the prioritisation of chemicals (Keller et al., 2012). Another workshop, FuturTox II, held afterwards in 2014, discussed many of the same challenges, limitations, and issues outlined in this paper. The overall conclusions of the workshop were that many knowledge gaps such as biological modelling, genetic basis for genetic susceptibility, and system biology to name a few, needed to be filled (Knudsen et al., 2015).

Canada, consistent with recent regulatory efforts in many countries, is interested in the toxicological pathway-based vision for human health assessments relying on in vitro systems and predictive models to generate the data needed to evaluate chemical hazard. One of the foundational challenges that Canada's CMP faces is assessing the potential for risk to human health of substances that have limited traditional whole animal testing. Consequently, international efforts to increase knowledge and address the key challenges outlined here, while transparently communicating and sharing both uncertainties and limitations of new information, are important for the development of alternative acceptable scientifically sound methods for toxicity testing and tools for predicting adverse effects for use in regulatory risk assessment. Taking into account the consequential advances that have been made recently, the integration of emerging data and new technologies into the human health risk assessment paradigm in the near future remains promising in order to address regulatory requirements under CEPA 1999.

\section{References}

Adler, S., Basketter, D., Creton, S., Pelkonen, O., van Benthem, J., Zuang, V., Andersen, K.E., Angers-Loustau, A., Aptula, A., Bal-Price, A., Benfenati, E., Bernauer, U., Bessems, J., Bois, F.Y., Boobis, A., Brandon, E., Bremer, S., Broschard, T., Casati, S., Coecke, S., Corvi, R., Cronin, M., Daston, G., Dekant, W., Felter, S., Grignard, E., Gundert-Remy, U., Heinonen, T., Kimber, I., Kleinjans, J., Komulainen, H., Kreiling, R., Kreysa, J., Leite, S.B., Loizou, G., Maxwell, G., Mazzatorta, P., Munn, S., Pfuhler, S., Phrakonkham, P., Piersma, A., Poth, A., Prieto, P., Repetto, G., Rogiers, V., Schoeters, G., Schwarz, M., Serafimova, R., Tahti, H., Testai, E., van Delft, J., van Loveren, H., Vinken, M., Worth, A. and Zaldivar, J.M. (2011) 'Alternative (non-animal) methods for cosmetics testing: current status and future prospects-2010', Archives in Toxicology, Vol. 85, No. 5, pp.367-485.

Andersen, M.E. and Krewski, D. (2010) 'The vision of toxicity testing in the 21 st century: moving from discussion to action', Toxicological Sciences, Vol. 117, No. 1, pp.17-24.

AXLR8 (2016a) Overview: What is AXLR8? [online] http://www.axlr8.eu/overview/ (accessed 14 January 2016).

AXLR8 (2016b) Publications [online] http://www.axlr8.eu/publications/ (accessed 14 January 2016).

AXLR8 (2016c) News \& Events [online] http://www.axlr8.eu/newsevents/ (accessed 14 January 2016).

Barton-Maclaren, T.S., Darshan, S. and Mattison, D.R. (2016) Int. J. Risk Assessment and Management, Special Issue: Risk Science in 21 st Century, this special issue - accepted.

Bouhifd, M., Andersen, M.E., Baghdikian, C., Boekelheide, K., Crofton, K.M., Fornace Jr., A.J., Kleensang, A., Li, H., Livi, C. and Maertens, A. (2015) 'The human toxome project', ALTEX, Vol. 32, No. 2, pp.112-124.

Collins, F.S., Gray, G.M. and Bucher, J.R. (2008) 'Toxicology: transforming environmental health protection', Science, Vol. 319, No. 5865, pp.906-907. 
Conolly, R.B. (2009) 'Commentary on 'toxicity testing in the 21 st century: implications for human health risk assessment' by Krewski et al.', Risk Analysis, Vol. 29, No. 4, pp.480-481.

Cote, I., Anastas, P.T., Birnbaum, L.S., Clark, R.M., Dix, D.J., Edwards, S.W. and Preuss, P.W. (2012) 'Advancing the next generation of health risk assessment', Environmental Health Perspectives, Vol. 120, No. 11, pp.1499-1502.

Dix, D. (2013) 'Utilizing ToxCast data for high throughput risk characterization', RSI Training Seminar for Health Canada, 4 March 2013, University of Ottawa, Ottawa, Ontario.

Environment Canada (2007) Overview of the Existing Substances Program [online] https://www.ec.gc.ca/lcpe-cepa/default.asp?lang=En\&n=EE479482-1\&wsdoc= 715BA6D1-03F3-A724-B164-901EDE6723C3 (accessed 14 January 2016).

Environment Canada (2013) Categorization of Existing Substances [online] http://www.ec.gc.ca/lcpe-cepa/default.asp?lang=En\&n=5F213FA8-1\& wsdoc=1695F8D0-5CC4-EDA1-AF63-6F23A94064DD (accessed 14 January 2016).

Environment Canada (2015) List of Substances [online] http://www.ec.gc.ca/ lcpe-cepa/default.asp?lang=En\&n=EE479482-1 (accessed 14 January 2016).

European Chemicals Agency (ECHA) (2016) REACH [online] $\mathrm{http}: / /$ echa.europa.eu/web/guest/regulations/reach/ (accessed 14 January 2016).

European Commission (2013) Executive Summary - The 7th Amendment to the Cosmetics Directive [online] http://ec.europa.eu/consumers/sectors/cosmetics/files/doc/antest/ \%282\%29_executive_summary_en.pdf (accessed 14 January 2016).

Gangwal, S., Reif, D.M., Mosher, S., Egeghy, P.P., Wambaugh, J.F., Judson, R.S. and Hubal, E.A. (2012) 'Incorporating exposure information into the toxicological prioritization index decision support framework', The Science of the Total Environment, Vols. 435-436, pp.316-325.

Government of Canada (1999) Canadian Environmental Protection Act, 1999. S.C., 1999, c. 33. Part III, Vol. 22, No. 3 [online] http://laws-lois.justice.gc.ca/PDF/C-15.31.pdf (accessed 14 January 2016).

Government of Canada (2007) Canada's System for Addressing Chemicals [online] http://www.chemicalsubstanceschimiques.gc.ca/approach-approche/system-eng.php (accessed 14 January 2016).

Greenberg, M. and Lowrie, K. (2009) 'Toxicity testing in the 21st century', Risk Analysis, Vol. 29, No. 4, pp.471-473.

Hartung, T. and McBride, M. (2011) 'Food for thought ... on mapping the human toxome', ALTEX, Vol. 28, No. 2, pp.83-93.

Hartung, T., Blaauboer, B.J., Bosgra, S., Carney, E., Coenen, J., Conolly, R.B., Corsini, E., Green, S., Faustman, E.M., Gaspari, A. and Hayashi, M. (2010) 'An expert consortium review of the EC-commissioned report' alternative (non-animal) methods for cosmetics testing: current status and future prospects-2010', ALTEX, Vol. 28, No. 3, pp.183-209.

Hartung, T., Luechtefeld, T., Maertens, A. and Kleensang, A. (2013) 'Integrated testing strategies for safety assessments', ALTEX, Vol. 30, No. 1, pp.3-18.

Hattis, D. (2009) 'High-throughput testing-the NRC vision, the challenge of modeling dynamic changes in biological systems, and the reality of low-throughput environmental health decision making', Risk Analysis, Vol. 29, No. 4, pp.483-484.

Health Canada (2009) Categorization of Substances on the Domestic Substances, 31 October 2014 [online] http://www.hc-sc.gc.ca/ewh-semt/contaminants/existsub/categor/index-eng.php (accessed 14 January 2016).

Hsu, C-W., Huang, R., Attene-Ramos, M.S., Austin, C.P., Simeonov, A. and Xia, M. (2016) 'Advances in high-throughput screening technology for toxicology', IJRAM, Accepted.

Isaacs, K.K., Glen, W.G., Egeghy, P., Goldsmith, M.R., Smith, L., Vallero, D., Brooks, R., Grulke, C.M. and Özkaynak, H. (2014) 'SHEDS-HT: an integrated probabilistic exposure model for prioritizing exposures to chemicals with near-field and dietary sources', Environmental Science and Technology, Vol. 48, No. 21, pp.12750-12759. 
Judson, R., Houck, K., Martin, M., Knudsen, T., Thomas, R.S., Sipes, N., Shah, I., Wambaugh, J. and Crofton, K. (2014) 'In vitro and modelling approaches to risk assessment from the US Environmental Protection Agency ToxCast Programme', Basic \& Clinical Pharmacology \& Toxicology, Vol. 115, No. 1, pp.69-76.

Judson, R., Kavlock, R., Martin, M., Reif, D., Houck, K., Knudsen, T., Richard, A., Tice, R.R., Whelan, M., Xia, M. and Huang, R. (2013) 'Perspectives on validation of high-throughput assays supporting 21 st century toxicity testing', ALTEX, Vol. 30, No 1, pp.51-56.

Judson, R.S., Houck, K.A., Kavlock, R.J., Knudsen, T.B., Martin, M.T., Mortensen, H.M., Reif, D.M., Rotroff, D.M., Shah, I., Richard, A.M. and Dix, D.J. (2010) 'In vitro screening of environmental chemicals for targeted testing prioritization: the ToxCast project', Environmental Health Perspectives, Vol. 118, No. 4, pp.485-492.

Judson, R.S., Kavlock, R.J., Setzer, R.W., Cohen Hubal, E.A., Martin, M.T., Knudsen, T.B., Houck, K.A., Thomas, R.S., Wetmore, B.A. and Dix, D.J. (2011) 'Estimating toxicity-related biological pathway altering doses for high-throughput chemical risk assessment', Chemical Research in Toxicology, Vol. 24, No. 4, pp.451-462.

JTEH (2010) Journal of Toxicology and Environmental Health, Special Issue: The Future of Toxicity Testing, Part B, Vol. 13, Nos. 2-4, pp.163-384.

Kavlock, R. and Dix, D. (2010) 'Computational toxicology as implemented by the US EPA: providing high throughput decision support tools for screening and assessing chemical exposure, hazard and risk', Journal of Toxicology and Environmental Health, Part B, Vol. 13, Nos. 2-4, pp.197-217.

Kavlock, R., Chandler, K., Houck, K., Hunter, S., Judson, R., Kleinstreuer, N., Knudsen, T., Martin, M., Padilla, S., Reif, D., Richard, A., Rotroff, D., Sipes, N. and Dix, D. (2012) 'Update on EPA's ToxCast program: providing high throughput decision support tools for chemical risk management', Chemical Research and Toxicology, Vol. 25, No. 7, pp.1287-1302.

Kavlock, R.J., Austin, C.P. and Tice, R.R. (2009) 'Toxicity testing in the 21st century: implications for human health risk assessment', Risk Analysis, Vol. 29, No. 4, pp.485-487.

Keller, D.A., Juberg, D.R., Catlin, N., Farland, W.H., Hess, F.G., Wolf, D.C. and Doerrer, N.G. (2012) 'Identification and characterization of adverse effects in 21st century toxicology', Toxicological Sciences, Vol. 126, No. 2, pp.291-297.

Kleinstreuer, N., Strickland, J. and Casey, W. (2014) 'Predicting skin sensitization using 21st century toxicology', FutureTox II In: 2014 Annual Meeting Abstract Supplement, Society of Toxicology, Abstract 1062c Poster Board-547.

Kleinstreuer, N.C., Judson, R.S., Reif, D.M.,Sipes, N.S., Singh, A.V., Chandler, K.J., DeWoskin, R., Dix, D.J., Kavlock, R.J. and Knudsen, T.B. (2011) 'Environmental impact on vascular development predicted by high-throughput screening', Environmental Health Perspectives, Vol. 119, No. 11, pp.1596-1603.

Knudsen, T.B., Keller, D.A., Sander, M., Carney, E.W., Doerrer, N.G., Eaton, D.L., Compton Fitzpatrick, S., Hastings, K.L., Mendrick, D.L., Tice, R.R., Watkins, P.B. and Whelan, M. (2015) 'FutureTox II: in vitro data and in silico models for predictive toxicology', Toxicological Sciences, Vol. 143, No. 2, pp.256-267.

Krewski, D., Westphal, M., Andersen, M.E., Paoli, G.M., Chiu, W.A., Al-Zoughool, M., Croteau, M.C., Burgoon, L.D. and Cote, I. (2014) 'A framework for the next generation of risk science', Environmental Health Perspectives, Vol. 122, No. 8, pp.96-805.

Locke, P.A. and Myers Jr., D.B. (2011) 'A replacement-first approach to toxicity testing is necessary to successfully reauthorize TSCA', ALTEX, Vol. 28, No. 4, pp.266-272.

Locke, P.A., Westphal, M., Tischler, J., Hessler, K., Frasch, P., Myers Jr., B., and Krewski, D. (2016) 'Implementing toxicity testing in the 21 st century: challenges and opportunities', IJRAM, accepted.

MacKay, C., Davies, M., Summerfield, V. and Maxwell, G. (2013) 'From pathways to people: applying the adverse outcome pathway (AOP) for skin sensitization to risk assessment', ALTEX, Vol. 30, No. 4, pp.473-486. 
Martin, M.T., Knudsen, T.B., Reif, D.M., Houck, K.A., Judson, R.S., Kavlock, R.J. and Dix, D.J. (2011) 'Predictive model of rat reproductive toxicity from ToxCast high throughput screening', Biology of Reproduction, Vol. 85, No. 2, pp.327-339.

Miller, D. (2015) Personal Communication, Professor, NSERC Industrial Research Chair, Department of Chemistry, Carleton University, Ottawa, Canada.

National Research Council (NRC) (2007) Toxicity Testing in the 21st Century: A Vision and a Strategy, The National Academies Press, Washington, DC.

National Research Council (NRC) (2009) Science and Decisions: Advancing Risk Assessment, The National Academies Press, Washington, DC.

National Research Council (NRC) (2014) Review of EPA's Integrated Risk Information System (IRIS) Process, The National Academies Press, Washington, DC.

OECD (2016b) The Global Portal to Information on Chemical Substances: Participating Databases [online] http://www.echemportal.org/echemportal/page.action?pageID=2 (accessed 14 January 2016).

Organization for Economic Co-operation and Development (OECD) (2005) OECD Series on Testing and Assessment (Number 34): Guidance Document on the Validation and International Acceptance of New or Updated Test Methods for Hazard Assessment, No. ENV/JM/MONO(2005)14, OECD, Paris.

Organization for Economic Co-operation and Development (OECD) (2008) Report of a Workshop on Integrated Approaches to Testing and Assessment (IATA), No. 88 [online] http://www.oecd.org/officialdocuments/publicdisplaydocumentpdf/?cote=env/jm/mono $\% 2820$ 08\%2910\&doclanguage $=$ en (accessed 14 January 2016).

Organization for Economic Co-operation and Development (OECD) (2012b) The Adverse Outcome Pathway for Skin Sensitisation Initiated by Covalent Binding to Proteins Part 2: Use of the AOP to Develop Chemical Categories and Integrated Assessment and Testing Approaches, Series on Testing and Assessment, No. 168, Part 2 [online] http://www.oecd.org/ officialdocuments/publicdisplaydocumentpdf/?cote $=$ env/jm/mono(2012)10/part2\&doclanguag $\mathrm{e}=$ en (accessed 14 January 2016).

Organization for Economic Co-operation and Development (OECD) (2013) Guidance Document on Developing and Assessing Adverse Outcome Pathways, No. 184 [online] http://www.oecd.org/officialdocuments/publicdisplaydocumentpdf/?cote=env/jm/mono $\% 2820$ $13 \% 296 \&$ doclanguage $=$ en $($ accessed 14 January 2016).

Organization for Economic Co-operation and Development (OECD) (2014a) New Guidance Document on an Integrated Approach on Testing and Assessment (IATA) for Skin Corrosion and Irritation, Series on Testing and Assessment, No. 203 [online] http://www.oecd.org/ officialdocuments/publicdisplaydocumentpdf/?cote=env/jm/mono(2014)19\&doclanguage=en (accessed 14 January 2016).

Organization for Economic Co-operation and Development (OECD) (2014b) New Scoping Document on In Vitro and Ex Vivo Assays for the Identification of Modulators of Thyroid Hormone Signalling, No. 207 [online] http://www.oecd.org/officialdocuments/ publicdisplaydocumentpdf $/$ ?cote $=\mathrm{ENV} / \mathrm{JM} / \mathrm{MONO} \% 282014 \% 2923 \&$ doclanguage $=\mathrm{en}$ (accessed 14 January 2016).

Organization for Economic Co-operation and Development (OECD) (2014c) Guidance Document for Describing Non-Guideline In Vitro Test Methods, No. 211 [online] http://www.oecd.org/ officialdocuments/publicdisplaydocumentpdf/?cote $=\mathrm{ENV} / \mathrm{JM} / \mathrm{MONO} \% 282014 \% 2935 \&$ docla nguage $=$ en (accessed 14 January 2016).

Organization for Economic Co-operation and Development (OECD) (2015a) Chemical Safety and Biosafety: Testing of Chemicals [online] http://www.oecd.org/chemicalsafety/testing/ (accessed 14 January 2016). 
Organization for Economic Co-operation and Development (OECD) (2015b) History: From the HPV Chemicals Programme to the Cooperative Chemicals Assessment Programme [online] http://www.oecd.org/chemicalsafety/risk-assessment/ historyfromthehpvchemicalsprogrammetothecooperativechemicalsassessmentprogramme.htm (accessed 14 January 2016)

Organization for Economic Co-operation and Development (OECD) (2015c) Mutual acceptance data (MAD) [online] http://www.oecd.org/chemicalsafety/testing/ mutualacceptanceofdatamad.htm (accessed 14 January 2016).

Organization for Economic Co-operation and Development (OECD) (2015d) Report of the Workshop on a Framework for the Development and Use of Integrated Approaches to Testing and Assessment, No. 215 [online] http://www.oecd.org/officialdocuments/ publicdisplaydocumentpdf $/$ cote $=\mathrm{ENV} / \mathrm{JM} / \mathrm{MONO} \% 282015 \% 2922 \&$ doclanguage $=\mathrm{en}$ (accessed 14 January 2016).

Organization for Economic Co-operation and Development (OECD) (2016a) The Global Portal to Information on Chemical Substances: eChemPortal [online] http://www.echemportal.org/echemportal/page.action?pageID=1 (accessed 14 January 2016).

Organization for Economic Co-operation and Development (OECD) Proteins Part 1: Scientific Evidence, Series on Testing and Assessment No. 168, Part 1 [online] $\mathrm{http}: / /$ www.oecd.org/officialdocuments/publicdisplaydocumentpdf/?cote=env/jm/mono(2012) 10/part1\&doclanguage=en (accessed 14 January 2016).

Reif, D.M., Martin, M.T., Tan, S.W., Houck, K.A., Judson, R.S., Richard, A.M., Knudsen, T.B., Dix, D.J. and Kavlock, R.J. (2010) 'Endocrine profiling and prioritization of environmental chemicals using ToxCast data', Environmental Health Perspectives, Vol. 118, No. 2, pp.1714-1720.

Reif, D.M., Sypa, M., Lock, E.F., Wright, F.A., Wilson, A., Cathey, T., Judson, R.R. and Rusyn, I. (2013) 'ToxPi GUI: an interactive visualization tool for transparent integration of data from diverse sources of evidence', Bioinformatics, Vol. 29, No. 3, pp.402-403.

Rovida, C., Alépée, N., Api, A.M., Basketter, D.A., Bois, F.Y., Caloni, F., Corsini, E., Daneshian, M., Eskes, C., Ezendam, J., Fuchs, H., Hayden, P., Hegele-Hartung, C., Hoffmann, S., Hubesch, B., Jacobs, M.N., Jaworska, J., Kleensang, A., Kleinstreuer, N., Lalko, J., Landsiedel, R., Lebreux, F., Luechtefeld, T., Locatelli, M., Mehling, A., Natsch, A., Pitchford, J.W., Prater, D., Prieto, P., Schepky, A., Schüürmann, G., Smirnova, L., Toole, C., van Vliet, E., Weisensee, D. and Hartung, T. (2015) 'Integrated testing strategies (ITS) for safety assessment', ALTEX - Alternatives to Animal Experimentations, Vol. 32, No. 1, pp. $25-40$.

Schechtman, L.M. (2008) 'Internationally harmonized processes for test method evaluation, validation and regulatory acceptance: the role of OECD guidance document 34', ALTEX, Special Issue, Vol. 14, No. 1, pp.475-482.

Schoeters, G. (2010) 'The REACH perspective: toward a new concept of toxicity testing', Journal of Toxicology and Environmental Health: Part B, Critical Reviews, Vol. 13, Nos. 2/4, pp.232-241.

Shukla, S.J., Huang, R., Austin, C.P. and Xia, M. (2010) 'The future of toxicity testing: a focus on in vitro methods using a quantitative high-throughput screening platform', Drug Discovery Today, Vol. 15, Nos. 23-24, pp.997-1007.

Sipes, N.S., Martin, M.T., Reif, D.M., Kleinstreuer, N.C., Judson, R.S., Singh, A.V., Chandler, K.J., Dix, D.J., Kavlock, R.J. and Knudsen, T.B. (2011) 'Predictive models of prenatal developmental toxicity from ToxCast high-throughput screening data', Toxicological Sciences, Vol. 124, No. 1, pp.109-127.

Thomas, R.S., Philbert, M.A., Auerbach, S.S., Wetmore, B.A., Devito, M.J., Cote, I., Rowlands, J.C., Whelan, M.P., Hays, S.M., Andersen, M.E. and Meek, M.B. (2013) 'Incorporating new technologies into toxicity testing and risk assessment: moving from $21 \mathrm{st}$ century vision to a data-driven framework', Toxicological Sciences, Vol. 136, No. 1, pp.4-18. 
Tsuji, J.S. and Garry, M.R. (2009) 'Advances in toxicity testing herald improvements and challenges for risk assessment', Risk Analysis, Vol. 29, No. 4, pp.490-491.

US Environmental Protection Agency (US EPA) (2009) The US Environmental Protection Agency's Strategic Plan for Evaluating the Toxicity of Chemicals [online] http://nepis.epa.gov/Exe/ZyNET.exe/P1003351.TXT?ZyActionD=ZyDocument\&Client=EPA $\&$ Index $=2006+$ Thru $+2010 \&$ Docs $=\&$ Query $=\&$ Time $=\&$ EndTime $=\&$ SearchMethod $=1 \&$ TocRes trict $=\mathrm{n} \& \mathrm{Toc}=\&$ TocEntry $=\& Q$ Field $=\& Q$ FieldYear $=\& Q$ FieldMonth $=\& Q$ FieldDay $=\&$ IntQFiel $\mathrm{dOp}=0 \&$ ExtQFieldOp $=0 \&$ XmlQuery $=\&$ File $=\mathrm{D} \% 3 \mathrm{~A} \backslash$ zyfiles $\backslash$ Index\%20Data $\backslash 06$ thru $10 \backslash$ Txt $\backslash 000$ 00007\P1003351.txt\&User=ANONYMOUS\&Password=anonymous\&SortMethod $=\mathrm{h} \mid-\&$ MaximumDocuments $=1 \&$ FuzzyDegree $=0 \&$ ImageQuality $=$ r75g8/r75g8/x150y $150 \mathrm{~g} 16 / \mathrm{i} 425 \&$ Display $=\mathrm{p} \mid \mathrm{f} \&$ DefSeekPage $=\mathrm{x} \&$ SearchBack $=$ ZyActionL $\&$ Back $=$ ZyActionS\&BackDesc $=$ Resul ts $\% 20$ page \&MaximumPages $=1 \& Z y$ Entry $=1 \&$ SeekPage $=x \& Z y P U R L$ (accessed 14 January 2016).

US Environmental Protection Agency (US EPA) (2014) Interactive Chemical Safety for Sustainability (iCSS) Dashboard [online] http:/www.epa.gov/sites/production/files/ 2014-12/documents/css_dashboard_factsheet_11-25-14_.pdf (accessed 14 January 2016).

US Environmental Protection Agency (US EPA) (2015a) Next Generation Risk Assessment: Incorporation of Recent Advances in Molecular, Computational, and Systems Biology, Final Report, US Environmental Protection Agency, Washington, DC, EPA/600/R-14/004, 2014 [online] http://cfpub.epa.gov/ncea/risk/recordisplay.cfm?deid=286690 (accessed 14 January 2016).

US Environmental Protection Agency (US EPA) (2015b) Use of High Throughput Assays and Computational Tools; Endocrine Disruptor Screening Program; Notice of Availability and Opportunity for Comment, Federal Register [online] https://www.federalregister.gov/articles/ 2015/06/19/2015-15182/use-of-high-throughput-assays-and-computational-tools-endocrinedisruptor-screening-program-notice (accessed 14 January 2016).

US Environmental Protection Agency (US EPA) (2016a) Computational Toxicology Research [online] http://www.epa.gov/ncct/ (accessed 14 January 2016).

US Environmental Protection Agency (US EPA) (2016b) Welcome to iCSS ToxCast Dashboard [online] http://actor.epa.gov/dashboard/ (accessed 14 January 2016).

Wambaugh, J.F., Setzer, R.W., Reif, D.M., Gangwal, S., Mitchell-Blackwood, J., Arnot, J.A., Joliet, O., Frame, A., Rabinowitz, J., Knudsen, T.B. and Judson, R.S. (2013) 'High-throughput models for exposure-based chemical prioritization in the ExpoCast project', Environmental Science and Technology, Vol. 47, No. 15, pp.8479-8488.

Wetmore, B.A., Allen, B., Clewell, H.J., Parker, T., Wambaugh, J.F., Almond, L.M., Sochaski, M.A. and Thomas, R.S. (2014) 'Incorporating population variability and susceptible subpopulations into dosimetry for high-throughput toxicity testing', Toxicological Sciences, Vol. 142, No. 1, pp.210-224.

Wetmore, B.A., Wambaugh, J.F., Allen, B., Ferguson, S.S., Sochaski, M.A., Setzer, R.W., Houck, K.A., Strope, C.L., Cantwell, K. and Judson, R.S. (2015) 'Incorporating high-throughput exposure predictions with dosimetry-adjusted in vitro bioactivity to inform chemical toxicity testing', Toxicological Sciences, Vol. 148, No. 1, pp.121-136.

Wetmore, B.A., Wambaugh, J.F., Ferguson, S.S., Sochaski, M.A., Rotroff, D.M., Freeman, K., Clewell, H.J., Dix, D.J., Andersen, M.E., Houck, K.A. and Allen, B. (2012) 'Integration of dosimetry, exposure, and high-throughput screening data in chemical toxicity assessment', Toxicological Sciences, Vol. 125, No. 1, pp.157-174. 